\title{
A microscopy-based small molecule screen in primary neurons reveals neuroprotective properties of the FDA-approved anti-viral drug Elvitegravir
}

Simon F. Merz ${ }^{1}$ (D, C. Peter Bengtson ${ }^{1}$ (D), Clara Tepohl ${ }^{1}$, Anna M. Hagenston ${ }^{1}$ (D) Hilmar Bading ${ }^{1}$ (D) and Carlos Bas-Orth ${ }^{1,2^{*}}$

\begin{abstract}
Glutamate toxicity is a pathomechanism that contributes to neuronal cell death in a wide range of acute and chronic neurodegenerative and neuroinflammatory diseases. Activation of the N-methyl-D-aspartate (NMDA)-type glutamate receptor and breakdown of the mitochondrial membrane potential are key events during glutamate toxicity. Due to its manifold functions in nervous system physiology, however, the NMDA receptor is not well suited as a drug target. To identify novel compounds that act downstream of toxic NMDA receptor signaling and can protect mitochondria from glutamate toxicity, we developed a cell viability screening assay in primary mouse cortical neurons. In a proof-of-principle screen we tested 146 natural products and 424 FDA-approved drugs for their ability to protect neurons against NMDA-induced cell death. We confirmed several known neuroprotective drugs that include Dutasteride, Enalapril, Finasteride, Haloperidol, and Oxybutynin, and we identified neuroprotective properties of Elvitegravir. Using live imaging of tetramethylrhodamine ethyl ester-labelled primary cortical neurons, we found that Elvitegravir, Dutasteride, and Oxybutynin attenuated the NMDA-induced breakdown of the mitochondrial membrane potential. Patch clamp electrophysiological recordings in NMDA receptorexpressing HEK293 cell lines and primary mouse hippocampal neurons revealed that Elvitegravir does not act at the NMDA receptor and does not affect the function of glutamatergic synapses. In summary, we have developed a cost-effective and easy-to-implement screening assay in primary neurons and identified Elvitegravir as a neuro- and mitoprotective drug that acts downstream of the NMDA receptor.
\end{abstract}

Keywords: Excitotoxicity, Mitochondria, Neuroprotection, NMDA receptor, Glutamate toxicity, Dutasteride, Finasteride, Oxybutynin, Channelrhodopsin

\footnotetext{
* Correspondence: bas-orth@ana.uni-heidelberg.de

${ }^{1}$ Department of Neurobiology, Interdisciplinary Center for Neurosciences, Heidelberg University, Im Neuenheimer Feld 366, D-69120 Heidelberg, Germany

${ }^{2}$ Department of Medical Cell Biology, Institute for Anatomy and Cell Biology, Heidelberg University, Im Neuenheimer Feld 307, D-69120 Heidelberg, Germany
}

C C The Author(s). 2020 Open Access This article is licensed under a Creative Commons Attribution 4.0 International License, which permits use, sharing, adaptation, distribution and reproduction in any medium or format, as long as you give appropriate credit to the original author(s) and the source, provide a link to the Creative Commons licence, and indicate if changes were made. The images or other third party material in this article are included in the article's Creative Commons licence, unless indicated otherwise in a credit line to the material. If material is not included in the article's Creative Commons licence and your intended use is not permitted by statutory regulation or exceeds the permitted use, you will need to obtain permission directly from the copyright holder. To view a copy of this licence, visit http://creativecommons.org/licenses/by/4.0/ The Creative Commons Public Domain Dedication waiver (http://creativecommons.org/publicdomain/zero/1.0/) applies to the data made available in this article, unless otherwise stated in a credit line to the data. 


\section{Introduction}

Glutamate toxicity is a basic pathomechanism that contributes to neuronal cell death in a wide range of acute and chronic neurodegenerative and neuroinflammatory diseases. This includes ischemic stroke, traumatic brain injury, Alzheimer's disease, Huntington's disease, Amyotrophic Lateral Sclerosis, and Multiple Sclerosis [1-4]. During acute trauma and chronic disease progression, excess glutamate is released from dysfunctional or dying neurons and/or from glial cells or activated immune cells. Under pathological conditions, binding of glutamate to the $N$-methyl-D-aspartate (NMDA) receptor on extrasynaptic neuronal membranes triggers signaling cascades that lead to mitochondrial permeability transition. This process is characterized by a breakdown of the mitochondrial membrane potential, excessive generation of reactive oxygen species, loss of ATP generation, and release of pro-apoptotic factors [5-7]. Accordingly, loss of mitochondrial structure and function is a key step in glutamate-mediated neuronal cell death $[3,8]$.

Despite its fundamental role in many neurodegenerative diseases, to date few clinically approved drugs are available that target glutamate toxicity. This is due-at least in part-to the fact that NMDA receptors have essential functions in neuronal physiology and thus are not well suited as drug targets [9-11]. We therefore aimed to identify novel compounds that act downstream of toxic NMDA receptor signaling and can protect mitochondria from glutamate toxicity. NMDA receptor signaling, however, is complex and its outcomes may differ based on NMDA receptor subunit composition, which is developmentally regulated. In addition, neuronal NMDA receptors are differentially localized to specialized subcellular compartments such as postsynaptic versus extrasynaptic membranes. Synaptic NMDA receptors promote physiological responses and cell survival, whereas extrasynaptic NMDA receptors promote cell death, possibly via coupling to specific second messenger cascades [9, 12-14]. This molecular and cell biological complexity is difficult, if not impossible, to recapitulate in cell lines. To overcome this limitation, we developed an automated microscopy-based screening assay in primary mouse cortical neurons. As a proof of principle, we screened a commercially available library of 424 FDA-approved drugs. Using our assay, we confirmed several known neuroprotective drugs and identified the anti-retroviral drug Elvitegravir as a neuro- and mitoprotective compound.

\section{Materials and methods}

\section{Animals}

C57BL/6NCrl mice (Charles River) were used in this study. Animals were maintained in pathogen-free and light- (12 h light/12 h dark) and temperature-controlled $\left(22^{\circ} \mathrm{C} \pm 2{ }^{\circ} \mathrm{C}\right)$ conditions. Food (LasVendi Rod 16 or Rod 18) and water were available ad libitum. Animals were housed in conventional cages with ABBEDD LT-E-001 bedding material. Animal welfare was assessed daily by staff of the animal facility. All procedures were carried out in accordance with German guidelines for the care and use of laboratory animals and with the European Community Council Directive 2010/63/EU, and had full Home Office ethical approval (University of Heidelberg Animal Welfare Office and Regierungspraesidium Karlsruhe).

\section{Preparation of primary cortical neurons}

Cortical neurons from newborn C57BL/6NCrl mice of both sexes were prepared and maintained as described previously [15]. In brief, 40,000 cells per well were seeded into Poly-D-Lysine coated 96-well plates (BD Biocoat 356,640) and were grown in Neurobasal-A medium (Life Technologies) supplemented with B27 (Life Technologies), $0.5 \mathrm{mM}$ glutamine, and $1 \%$ rat serum. To prevent the proliferation of glial cells, cytosine $\beta$-D-arabinofuranoside (Sigma-Aldrich, $2.8 \mu \mathrm{M}$ ) was added on day in vitro (DIV) 3. On DIV 8 growth medium was exchanged to a defined minimal medium consisting of a mixture of buffered salt-glucose-glycine (SGG) solution [10 mM Hepes (pH 7.4), $114 \mathrm{mM} \mathrm{NaCl}$, $26.1 \mathrm{mM} \mathrm{NaHCO}, 5.3 \mathrm{mM} \mathrm{KCl}, 1 \mathrm{mM} \mathrm{MgCl} 2,2 \mathrm{mM}$ $\mathrm{CaCl}_{2}, 30 \mathrm{mM}$ glucose, $1 \mathrm{mM}$ glycine, $0.5 \mathrm{mM}$ sodium pyruvate, and $0.001 \%$ phenol red] and phosphate-free Eagle's minimum essential medium (MEM, Life Technologies) (9:1 vol:vol), supplemented with insulin $(7.5 \mu \mathrm{g} / \mathrm{ml})$, transferrin $(7.5 \mu \mathrm{g} / \mathrm{mI})$, and sodium selenite $(7.5 \mathrm{ng} / \mathrm{ml})$ (ITS supplement, Sigma-Aldrich). Experiments were performed after a culturing period of 10-12 DIV.

\section{Preparation of primary hippocampal neurons}

Primary mouse hippocampal neurons were prepared and maintained as previously described [15]. Neurons were plated onto $12 \mathrm{~mm}$ diameter glass coverslips. All patch clamp recordings were performed after a culturing period of 14 to 18 DIV during which hippocampal neurons expressing markers for either glutamate ( 90\% of neurons) or GABA ( 10\% of neurons) develop a rich network of processes, express functional NMDA-type and 2-amino-3-(3-hydroxy-5-methyl-isoxazol-4-yl) propanoic acid (AMPA)/kainate-type glutamate receptors, and form synaptic contacts [16]. Viral transduction of neurons with the channelrhodopsin-2 (ChRII) mutant T159C [17] combined with an mCherry marker took place on DIV 8.

\section{Small molecule libraries}

A small molecule library containing 424 FDA approved compounds provided as $10 \mathrm{mM}$ stock solutions in 
DMSO, and a natural product library containing 146 compounds provided as $10 \mathrm{mM}$ stock solutions in DMSO were purchased from SelleckChem. See Tables S1 and S2 for details.

\section{Drug treatment for cell death assay}

On DIV 10, compounds were applied to the cells reaching an end concentration of $10 \mu \mathrm{M}$. Cells were incubated for $30 \mathrm{~min}$ at $37^{\circ} \mathrm{C}, 5 \% \mathrm{CO}_{2}$ before adding NMDA $(30 \mu \mathrm{M})$. Cells were incubated for another $10 \mathrm{~min}$ in the incubator, then washed twice with defined minimal medium containing $10 \mu \mathrm{M}$ of the respective compound and incubated for an additional $20 \mathrm{~h}$ before readout. Untreated (no NMDA) and NMDA-only stimulated wells were treated with $0.1 \%$ DMSO.

\section{Cell death assay}

Twenty hours after NMDA treatment, cells were fixed and stained by direct addition of a mixture of formaldehyde (4\% final concentration) and Hoechst $33258(2 \mu \mathrm{g} /$ $\mathrm{ml}$ final concentration). After $15 \mathrm{~min}$ of incubation at room temperature, cells were washed twice with phosphate buffered saline. Subsequently, 12 images per well were recorded with a 12-bit camera (Hamamatsu 480, 674) attached to an automated fluorescence microscope (Olympus IX81, objective UPlanSApo 10x, NA: 0.4, DAPI filter set) at the Advanced Biological Screening Facility, BioQuant, Heidelberg. Dead neurons were identified by amorphous or shrunken nuclei using CellProfiler and CellProfiler Analyst software [18]. For all cell death analyses the experimental unit $(\mathrm{N})$ is defined as an independent experiment using an independent neuronal preparation. For each independent experiment, data from 3 replicate wells (i.e., from 36 images), representing an average of 3000 cells was analyzed per condition. The survival rate $S$ was calculated by dividing the number of living cells by the total number of cells. The survival rate was then used to calculate the protection score according to $\frac{S(\text { compound })-S(\text { vehicle })}{S(\text { untreated })-S(\text { vehicle })} \times 100=\%$ protection, where 'compound' refers to compound + NMDA treatment, 'vehicle' refers to vehicle + NMDA treatment, and 'untreated' refers to DMSO control. Some compounds exhibited strong neurotoxic effects that resulted in low total numbers of cells. This precluded a reliable calculation of a protection score. Therefore, protection scores were not determined for compounds that resulted in a total cell count of less than $10 \%$ of the average cell count from all screening experiments (see Table S2). In addition, protection scores could not be calculated for the compounds Mitoxantrone and Cerubidine (Daunorubicin) because their color interfered with the fluorescence-based assay.

\section{Measurement of mitochondrial membrane potential changes}

Live imaging was performed in 96-well plates (BD Biocoat 356,640$)$ on an automated fluorescence microscope (Olympus IX81, objective UPlanSApo 10x, NA: 0.4) at the Advanced Biological Screening Facility, BioQuant, Heidelberg. Cells were incubated for at least $2 \mathrm{~h}$ with 50 $\mathrm{nM}$ tetramethylrhodamine ethyl ester (TMRE) in $100 \mu \mathrm{l}$ imaging buffer (SGG without bicarbonate and phenol red) per well prior to adding compounds $(10 \mu \mathrm{M})$. After $20 \mathrm{~min}$ of compound incubation, cells were stimulated with $30 \mu \mathrm{M}$ NMDA. Time-lapse imaging commenced immediately after NMDA application. Due to initial autofocus determination, acquiring the first image of all wells took $124 \mathrm{~s}$ for each 96-well plate. Subsequently, one field of view per well in each of 25 wells was imaged in parallel for $20 \mathrm{~min}$ at a rate of one image every $30 \mathrm{~s}$. 3-6 replicate wells per compound and 5-10 replicate wells of untreated and NMDA only-treated cells were imaged in each independent experiment. Fluorescence intensity was measured using FIJI with the StackReg plugin $[19,20]$. In short, images of each well were aligned and background corrected, and fluorescence intensity was measured over time within automatic thresholdbased regions of interest. Loss of TMRE signal was quantified by determining the area under the curve with Prism software (GraphPad).

\section{Automated patch clamp}

HEK293 cell lines stably expressing human GluN1 (UniProt ID Q05586)/GluN2A (Uniprot Q12879) (CT6120, ChanTest Cell Lines, Charles river) or human GluN1/ GluN2B (Uniprot Q13224) (CTN6121, ChanTest Cell Lines, Charles River) NMDA receptors were maintained in Dulbecco's Modified Eagle's medium (DMEM) supplemented with $10 \%$ FBS, sodium pyruvate, nonessential amino acids, and $0.5 \%$ penicillin/streptomycin at $37^{\circ} \mathrm{C}$ and $5 \% \mathrm{CO}_{2}$. Expression of GluN1, GluN2A, and GluN2B was induced by tetracycline. Voltage clamp recordings were performed using the Sophion Qube platform which performs 384 parallel and independent patch-clamp recordings with digitally controlled microfluidics (Tcan D300) on a disposable, 10-hole QChip. Data was filtered for quality control thresholds for seal resistance and holding current. The following extracellular solution was used (in $\mathrm{mM}$ ): $\mathrm{NaCl}, 145 ; \mathrm{KCl}, 4 ; \mathrm{HEPE}$ S, 10; Glucose, 10; $\mathrm{CaCl}_{2}, 2$; $\mathrm{pH}$ 7.4. The following intracellular solution was used (in $\mathrm{mM}$ ): $\mathrm{CsF}, 70 ; \mathrm{CsCl}, 70$; HEPES, 10; EGTA, 1; 316 mOsm, pH 7.2. IC $_{50}$ estimates for Elvitegravir and NMDA receptor antagonists were generated at $-70 \mathrm{mV}$ in $\mathrm{Mg}^{2+}$-free extracellular solution against responses to glycine $(100 \mu \mathrm{M})$ plus NMDA $(90 \mu \mathrm{M}$ for GluN1/GluN2A and $40 \mu \mathrm{M}$ for GluN1/ GluN2B). These concentrations represent saturating 
glycine and $\mathrm{EC}_{80} \mathrm{NMDA}$ concentrations for glutamate receptor activation as determined a priori for each cell line.

\section{Whole-cell patch clamp recordings}

Whole-cell patch clamp recordings were made at $32{ }^{\circ} \mathrm{C}$ from DIV14-18 primary hippocampal neurons plated on coverslips secured with a platinum ring in a recording chamber (Open access chamber-1, Science Products $\mathrm{GmbH}$, Hofheim, Germany) mounted on a fixed-stage upright microscope (BX51WI, Olympus) with heated inline perfusion (TC324B, Warner Instruments Corporation) running constantly at $2-3 \mathrm{ml}$ per minute. Recordings were made with a Multiclamp $700 \mathrm{~B}$ amplifier, digitized through a Digidata 1322A A/D converter and quantified using pClamp 10 software (Molecular Devices, CA, USA). Access resistance (range: 8-20 M 2 ) was monitored regularly during voltage clamp recordings and data was rejected if changes greater than 20\% occurred. Patch electrodes (3-5 M $\Omega$ ) were made from borosilicate glass $(1.5 \mathrm{~mm}$, WPI, Sarasota, FL, USA). The intracellular solution was composed of (in $\mathrm{mM}$ ): cesium gluconate (90), HEPES (10), EGTA (5), $\mathrm{CaCl}_{2}$ (0.5), tetraethylammonium (10), QX-314 (4), ATP (4), GTP (0.5), $\mathrm{K}_{2}$-phophocreatine (10). The extracellular solution was composed of (in $\mathrm{mM}$ ): $\mathrm{NaCl}$ (125), $\mathrm{KCl}$ (3.5); $\mathrm{MgCl}_{2}$ (1.3), $\mathrm{NaH}_{2} \mathrm{PO}_{4}$ (1.2), $\mathrm{CaCl}_{2}$ (2.4), glucose (10), $\mathrm{NaHCO}_{3}$ (21); equilibrated with $95 \% \mathrm{O}_{2}$ and $5 \% \mathrm{CO}_{2} ; \mathrm{pH} 7.35$; $325 \mathrm{mOsm}$. Where indicated, $\mathrm{MgCl}_{2}$ was increased to 4 $\mathrm{mM}$ to stabilize the membrane potential and suppress recurrent EPSC generation. For recordings of AMPA receptor-mediated EPSCs, the NMDA receptor blocker, dizocilpine maleate $(\mathrm{MK}-801,10 \mu \mathrm{M})$, and the $\mathrm{GABA}_{\mathrm{A}}$ receptor blocker, SR 95531 hydrobromide (gabazine, $2 \mu \mathrm{M})$, were added to the extracellular solution. For recordings of NMDA receptor-mediated EPSCs, the AMPA receptor blocker, 2,3-Dioxo-6-nitro-1,2,3,4-tetrahydrobenzo [f]quinoxaline-7-sulfonamide disodium salt (NBQX, $5 \mu \mathrm{M})$, gabazine $(2 \mu \mathrm{M})$, and the NMDA receptor coagonist, glycine $(100 \mu \mathrm{M})$, were added to the extracellular solution. AMPA and NMDA receptor-mediated EPSCs were verified by the addition of NBQX $(5 \mu \mathrm{M})$ or D-(L)-2-Amino-5-phosphonopentanoic acid (DL-APV, $50 \mu \mathrm{M})$, respectively. ChRII is a light-gated cation channel that has been extracted from the green algae Chlamydomonas reinhardtii. Fluorescent excitation light was generated by a $470 \mathrm{~nm}$ LED for ChRII excitation and by a $594 \mathrm{~nm}$ LED for mCherry (pE2, CoolLEDs, Andover, UK). Excitation light was passed through ET470/ 40 and HQ570/20 cleanup filters and emission light was passed through ET585 long-pass dichroic and ET620/60 emission filters (AHF Analysetechnik, Tuebingen, Germany). Four hundred-seventy nm LED triggering was controlled directly from the digitizer.

\section{Statistical analyses}

Statistical analyses were performed with Estimation Statistics Beta [21], Prism (GraphPad) or OriginPro (OriginLab). To determine bias-corrected and accelerated confidence intervals in Estimation Statistics Beta, 5000 bootstrap samples were taken. All $\mathrm{IC}_{50}$ or $\mathrm{EC}_{50}$ values were generated using a logistic fit to the Hill equation. Experimental units $(\mathrm{N})$ for each experiment are defined in the respective methods sections and in the figure legends.

\section{Illustrations}

Graphs were generated with Prism and Estimation Statistics Beta [21]. Heatmaps were generated with Heatmapper [22]. Figures were assembled with Adobe Photoshop and Adobe Illustrator.

\section{Results}

\section{Development of a robust cell death screening assay in} primary neurons

To analyze excitotoxic cell death, primary cortical neurons were treated with $30 \mu \mathrm{M}$ NMDA for $10 \mathrm{~min}$ followed by two washes with fresh medium, and cell death was assessed after $20 \mathrm{~h}$ (Fig. 1a). This protocol has previously been shown to robustly induce neuronal cell death that can be attenuated by various pharmacological pre-treatments or genetic manipulations [15, 23, 24].

When choosing a simple and cost-effective assay to quantify cell death in cultured primary neurons, we took advantage of the fact that necrotic neurons can be readily identified by the distinct morphology of their nuclei and thus be distinguished from live cells $[15,23,25]$. Therefore, we stained fixed neurons with the nuclear dye Hoechst 33258 and used the CellProfiler Analyst tool [18] to classify cells as live or dead (Fig. 1b). Quantifying the number of both dead and live cells within each well provides an internal normalization for the total number of cells per analysis region. This reduces the variability of the assay without the need for additional assays such as quantification of total protein amount per well that is typically used in enzyme-based cell viability assays.

We initially performed cell death assays using primary neurons grown in 24-well, 96-well, and 384-well plates and found that the 96-well format provided the best trade-off between sample throughput, operability, and cell viability. Because primary neurons are highly sensitive to osmotic stress that results from media evaporation [26], we did not seed neurons into the outermost wells of the 96-well plates, which are affected most by evaporation.

To further benchmark our assay, we assessed the well-to-well variability of cell viability, which we expected to be larger in primary neurons than in the 


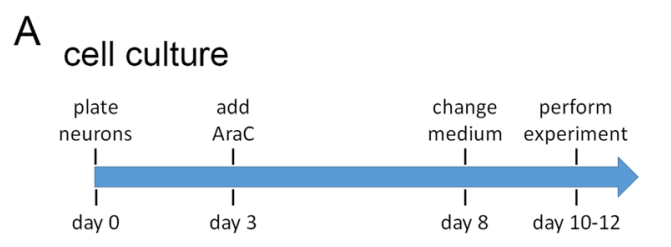

B

experiment


Fig. 1 Development of a screening assay using primary neurons. a Schematic representation of the workflow. $\mathbf{b}$ Example images illustrating data analysis with CellProfiler (segmentation) and CellProfiler Analyst (training and classification). Dead neurons can be identified based on their shrunken and brightly stained nuclei. c Heatmap illustrating the variability of neuronal viability between technical replicate wells. Z-scores (the number of standard deviations by which each value differs from the mean) were calculated independently for control and NMDA-treated wells. $\mathbf{d}$ Comparison of cell viability values that were either calculated for each single well of the plate shown in c, or based on the summed cell counts from groups of two, three, or five wells from that plate. Error bars indicate the SD

cell lines typically used in viability analyses. In an experiment in which 30 wells in a 96-well plate were treated with NMDA and 30 wells were left untreated, NMDA robustly reduced survival, whereas cell survival in individual untreated wells was rather variable (Fig. 1c, d). Viability in untreated wells ranged from 40 to $94 \%$ with a mean of $75.7 \%$ and a standard deviation of $12.27 \%$. Calculating viability based on summed cell counts from two, three, or five replicate wells reduced the standard deviation to $5.8,5.48 \%$, or $3.07 \%$, respectively (Fig. 1d). Therefore, as a trade-off between robustness and throughput, we decided to test each compound in triplicate wells in our proof-of-principle screens, such that each data point was derived from the summed cell counts in three wells.

\section{Screening of small molecule libraries}

As a proof of principle, we next used our assay to screen two commercially available drug libraries. In these screens, primary cortical cells were incubated with test compounds at $10 \mu \mathrm{M}$ concentration for 30 min before addition of $30 \mu \mathrm{M}$ NMDA. After $10 \mathrm{~min}$ NMDA treatment, cells were washed with fresh medium and kept in the presence of test compounds for $20 \mathrm{~h}$ until assessment of cell viability. First, we screened a library of 146 structurally diverse natural products (Fig. 2a, Table S1). In this screen, protection 



Fig. 2 Summary data of protection scores that were obtained in the small molecule screens. a-b Binned histogram (left) and scatter plot (right) of protection scores from compounds in the natural product library $\mathbf{a}$ and the library of FDA-approved drugs $\mathbf{b}$. The five most protective compounds and compounds that were studied in follow-up experiments are indicated by red dots in the scatter plot and are labelled as $D=$ Dutasteride, $\mathrm{G}=$ Grape seed extract, $\mathrm{E}=$ Eltrombopag, Elv = Elvitegravir, $\mathrm{H}=$ Haloperidol, $\mathrm{F}=$ Finasteride, I = Isoniazid, $\mathrm{O}=\mathrm{Oyxybutynin}$

scores ranged from $-5.3 \%$ (slightly toxic) to $32.2 \%$ (moderately protective). We then screened a library of 424 FDA-approved drugs. This library covers structurally diverse drugs from several fields such as oncology, cardiology, immunology, and neurology/ psychiatry. We found a number of compounds that exacerbated NMDA-induced cell death (negative protection scores), a majority of compounds that exhibited little to no effect on cell death, and 12 compounds that conferred $>50 \%$ protection from NMDA-induced cell death (Fig. 2b, Table S2). The latter include known neuroprotective compounds such as grape seed extract, Haloperidol, Enalapril (Vasotec), Finasteride, and Dutasteride, as well as novel candidates such as Elvitegravir.

\section{Characterization of selected hit compounds}

We selected five neuroprotective compounds from our screen for further characterization. First, we confirmed their neuroprotective effect in independent experiments using the same method as for the initial screen (Fig. 3a). We next assessed if these compounds confer neuroprotection when applied after the NMDA insult. Such a post-insult protective effect would be desirable for potential clinical applications. Application of the compounds at $30 \mathrm{~min}$ or $2 \mathrm{~h}$ after NMDA washout, however, did not attenuate neuronal cell death (Fig. 3b). Following up on a recent study that reported toxic effects of Elvitegravir in primary rat cortical neurons [27], we assessed the effect of $48 \mathrm{~h}$ Elvitegravir treatment on our mouse cortical neurons. Similar to this previous study, we 




observed an $\sim 34 \%$ decrease of viable cells after $48 \mathrm{~h}$ treatment with $10 \mu \mathrm{M}$ Elvitegravir (Fig. 3c). Finally, we asked if the compounds are able to attenuate NMDAinduced mitochondrial membrane potential breakdown, a key event in excitotoxic cell death [3]. We used the cationic dye TMRE to visualize the mitochondrial membrane potential and its NMDA-induced breakdown in live cells $[28,29]$. To facilitate the analysis of all five 
compounds in parallel, TMRE live imaging was performed in 96-well plates on an automated microscope (Fig. 4a, supplementary Movie 1). In untreated cells,
TMRE fluorescence remained constant throughout the 20-min observation time. In contrast, application of $30 \mu \mathrm{M}$ NMDA resulted in rapid loss of mitochondrial

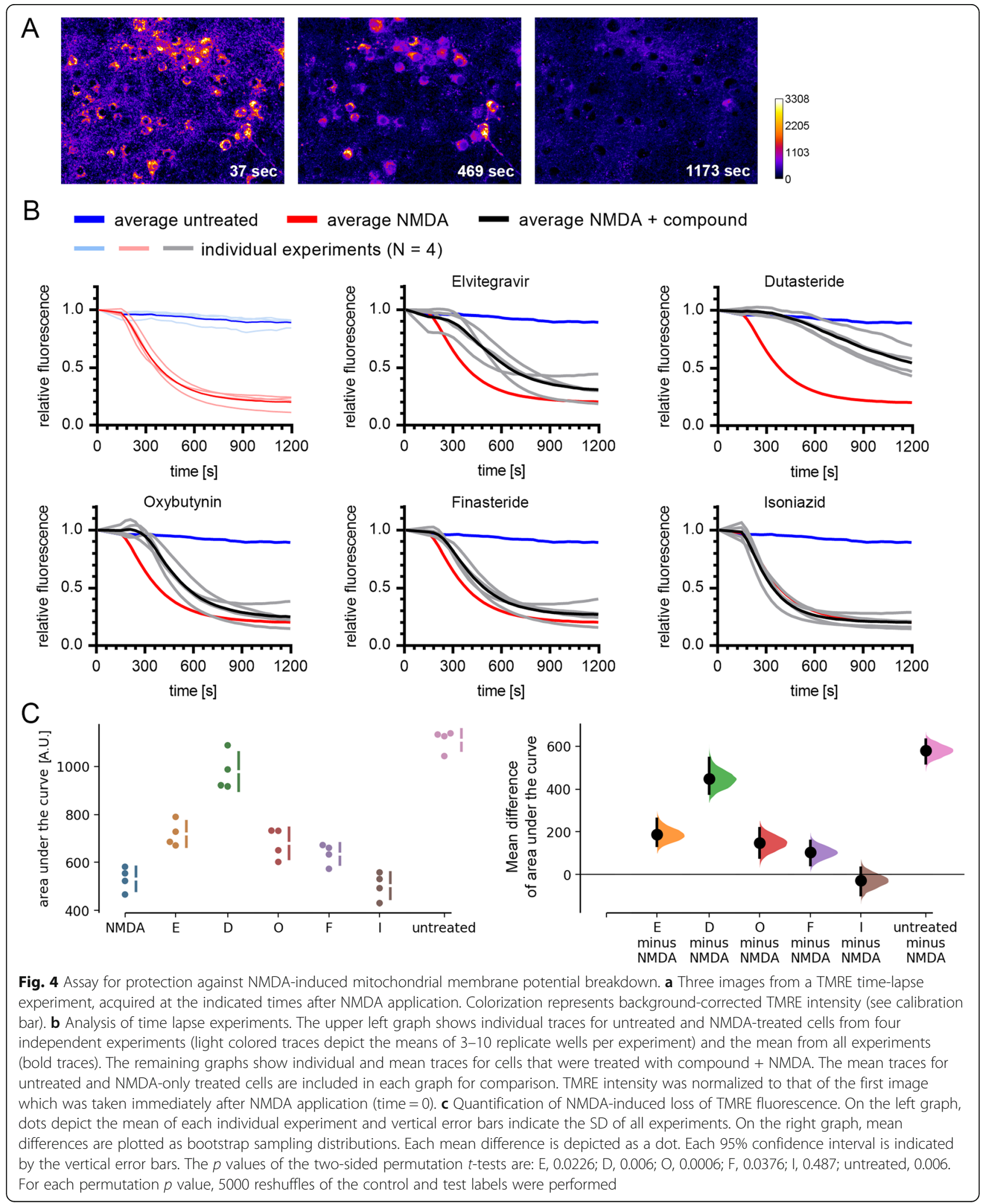


TMRE fluorescence, indicative of mitochondrial depolarization (Fig. 4b, supplementary Movie 1). Pretreatment with Elvitegravir, Dutasteride, or Oxybutynin resulted in delayed and less pronounced loss of TMRE fluorescence upon NMDA treatment, revealing mitoprotective properties of these compounds (Fig. 4b, c).

\section{Pharmacological characterization of Elvitegravir at NMDA receptors}

Since Elvitegravir has not previously been described as neuroprotective, we focused on that compound and aimed to elucidate its neuroprotective mechanism. Inhibition of NMDA receptors by Elvitegravir would provide a straightforward explanation for its neuroprotective properties. As discussed above, however, the NMDA receptor is not well-suited as a drug target. To help evaluate the clinical potential of Elvitegravir, we thus tested if this compound acts directly at NMDA receptors rather than at a downstream target. To assess the $\mathrm{IC}_{50}$ of Elvitegravir for NMDA receptor-mediated currents we employed a high throughput automated patch clamp system to measure NMDA receptor currents in HEK293 cells stably expressing GluN1/GluN2A or GluN1/GluN2B NMDA receptors. Currents were measured at $-70 \mathrm{mV}$ in $\mathrm{Mg}^{2+}$-free solutions. Analysis found that Elvitegravir had no effects on NMDA-evoked currents for either GluN1/GluN2A or GluN1/GluN2B receptors $\left(\mathrm{IC}_{50}>300 \mu \mathrm{M}\right)$ (Fig. 5). Thus Elvitegravir's protection against NMDA-induced toxicity is not mediated by direct antagonism of NMDA receptors.

\section{Measuring optogenetically evoked AMPA and NMDA receptor-mediated synaptic currents with patch clamp recordings}

In any potential in vivo application, compounds that protect against glutamate-induced excitotoxicity should not interfere with glutamatergic synaptic transmission, which is critical for the plasticity underlying learning and memory. To assess the effects of Elvitegravir on synaptic glutamate receptor function in a neuron, we performed whole-cell patch clamp recordings in primary hippocampal cultures (DIV 14-16) from mice. AMPA and NMDA receptor-mediated synaptic contacts in such cultures have previously been shown to mediate network activity whose NMDA receptor-dependent modulation serves as an in vitro model for synaptic plasticity [16]. Synaptic AMPA and NMDA receptor function was assessed from single and paired pulse EPSC events evoked via the optogenetic stimulation of action potentials in presynaptic neurons expressing ChRII. This optogenetic method was chosen over traditional electrical stimulation due to difficulties with the latter technique in achieving stable recordings of single EPSC responses over prolonged recordings in monolayer cultures, especially in the presence of $\mathrm{GABA}_{\mathrm{A}}$ receptor antagonists, which promote epileptiform activity.

\section{Verification of the stability of ChRII responses}

To investigate the effects of Elvitegravir on synaptic transmission we used light activation of ChRII to evoke action potentials in ChRII and mCherry co-expressing presynaptic neurons for the generation of EPSCs in postsynaptic ChRII-negative cells. To characterize, optimize, and verify the stability of our method, we first performed patch clamp recordings from mCherry-positive neurons. These neurons exhibited light-activated currents (273 $\mathrm{pA}$ to $1103 \mathrm{pA}$ ) in 17 out of 17 cells, confirming coinfection with the ChRII-encoding recombinant adenoassociated virus (rAAV). These currents showed the expected rapid inactivation over a $100 \mathrm{~ms}$ light pulse which was unaffected by the application of either DMSO $(0.1 \%)$ or Elvitegravir $(20 \mu \mathrm{M}$ dissolved in DMSO to a final concentration of $0.1 \%$ ) (Fig. 6). Recovery from inactivation was apparent within $30 \mathrm{~s}$ in accordance with the published recovery time $\left(\tau_{\text {rec }}\right)$ of $16 \mathrm{~s}$ [17]. These observations suggest that ChRII is not affected by Elvitegravir.

\section{The effect of Elvitegravir on synaptic AMPA and NMDA receptor function}

AMPA receptor-mediated EPSCs were recorded from mCherry- and ChRII-negative cells and pharmacologically isolated with $\mathrm{GABA}_{\mathrm{A}}$ and NMDA receptor blockers. In addition, to suppresses recurrent activity, which is promoted by $\mathrm{GABA}_{\mathrm{A}}$ blockers, we increased the extracellular $\mathrm{Mg}^{2+}$ concentration to $4 \mathrm{mM}$. The DMSO used to dissolve Elvitegravir was added during baseline recordings to an equivalent of $0.01 \%$. Under these conditions, AMPA receptor-mediated EPSCs recorded at a holding potential of $-70 \mathrm{mV}$ were evoked with $0.7 \mathrm{~ms}$ light pulses at $30 \mathrm{~s}$ intervals until stable response amplitudes were achieved. Further addition of Elvitegravir $(20 \mu \mathrm{M})$ did not affect AMPA EPSC amplitudes over 10 to $20 \mathrm{~min}$ (Fig. 7a). Immediate and almost complete blockade, however, was achieved with the addition of the AMPA receptor blocker NBQX.

The ratio of responses to a pair of synaptic stimuli provides an indication of neurotransmitter release probability [30-32]. A relative decrease in the second response is indicative of an increased synaptic transmitter release probability [33]. This is typically quantified as a paired pulse ratio (PPR), calculated as the ratio of the second to the first postsynaptic response amplitude. To assess any impact of Elvitegravir on synaptic glutamate release probability, we used paired light pulses which produced a maximal PPR of around 0.9 using a $75 \mathrm{~ms}$ inter-pulse interval. Partial inactivation of ChRII reduces the second EPSC response amplitude and the magnitude 
A


$\mathrm{B}$
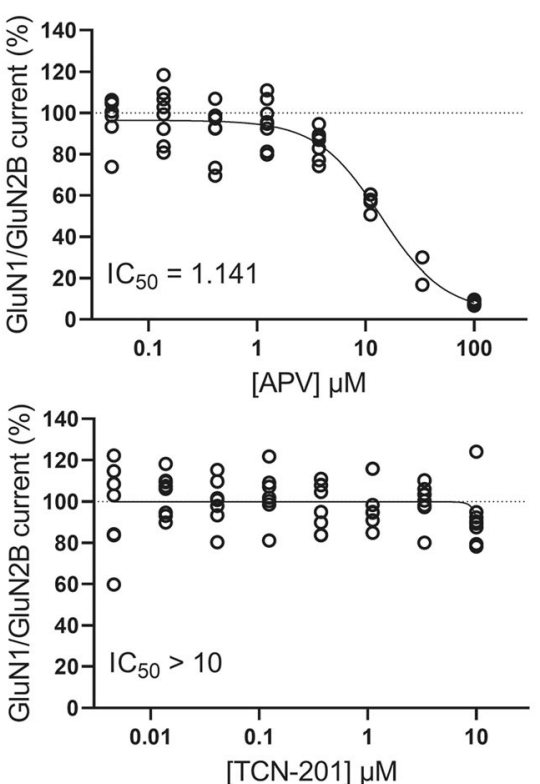
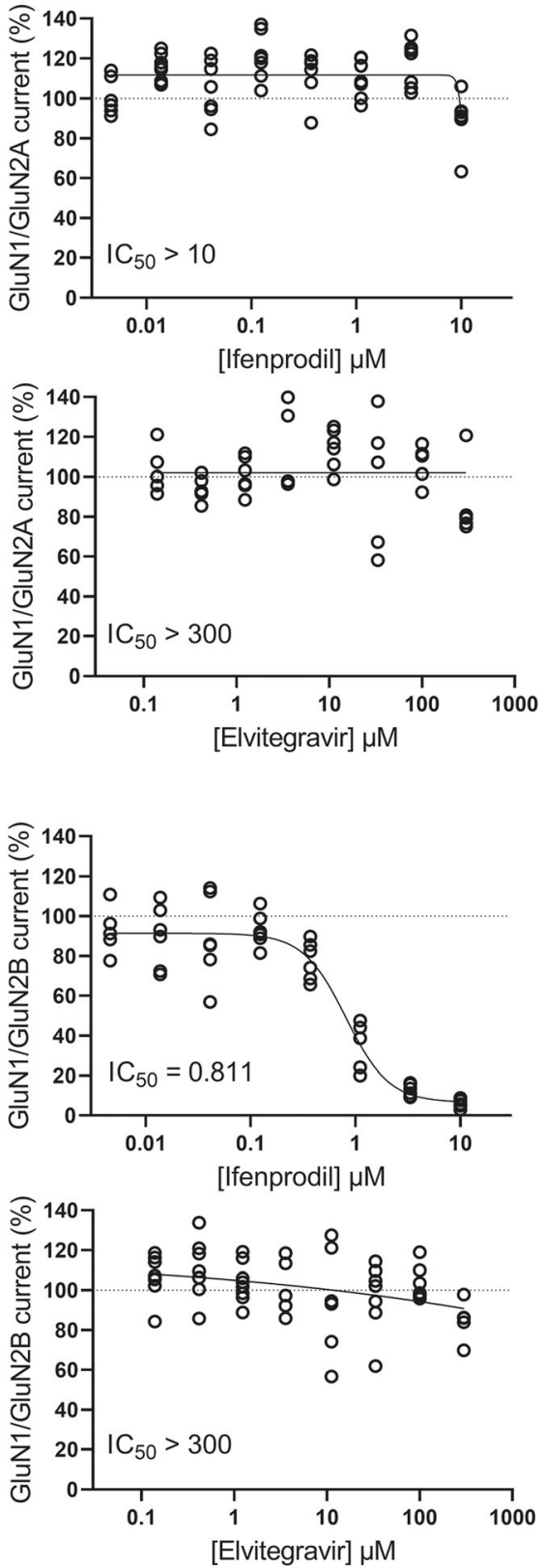

Fig. 5 Elvitegravir does not affect NMDA receptor function in HEK293 cells. Automated patch clamp recordings were performed using the Sophion Qube platform to generate antagonistic dose-response curves of Elvitegravir and NMDA receptor antagonists, D-APV, Ifenprodil, and TCN-201 for human GluN1/GluN2A a or GluN1/GluN2B b NMDA receptors expressed in HEK293 cell lines. Responses to NMDA and glycine (see methods section) were recorded at $-70 \mathrm{mV}$ in $\mathrm{Mg}^{2+}$-free extracellular solutions and normalized to responses of the same cells recorded in the absence of Elvitegravir or antagonists. GluN1/GluN2A was blocked by the non-selective NMDA receptor antagonist, D-APV (IC 50 : $1.477 \mu M)$ and the selective GluN2A blocker, TCN-201 (IC 50 : $0.722 \mu \mathrm{M})$ but not the GluN2B antagonist, Ifenprodil $\left(\mathrm{IC}_{50}>10 \mu \mathrm{M}\right)$ or Elvitegravir $\left(\mathrm{C}_{50}>300 \mu \mathrm{M}\right)$. GluN1/GluN2B was blocked by the non-selective NMDA receptor antagonist, D-APV (IC $50: 1.141 \mu \mathrm{M})$ and the selective GluN2B blocker, Ifenprodil $\left(\mathrm{IC}_{50}: 0.811 \mu \mathrm{M}\right)$ but not the GluN2A antagonist, TCN-201 ( $\left(\mathrm{C}_{50}>10 \mu \mathrm{M}\right)$ or Elvitegravir $\left(\mathrm{IC}_{50}>300 \mu \mathrm{M}\right)$. Data are shown as individual cell values and a logistic fit of the Hill equation to the data from which $I_{50}$ values were estimated. $N=2-8$ cells from two independent experiments

of our PPRs in comparison to those from recordings using electrical stimulation [30-33]. Nonetheless, PPRs remained stable over prolonged recordings and were not affected by Elvitegravir application (Fig. 7b).
Finally, to assess the effect of Elvitegravir on synaptic NMDA receptor function we recorded NMDA receptormediated EPSCs at $+40 \mathrm{mV}$ in the presence of blockers of $\mathrm{GABA}_{\mathrm{A}}$ and AMPA receptors as well as elevated 


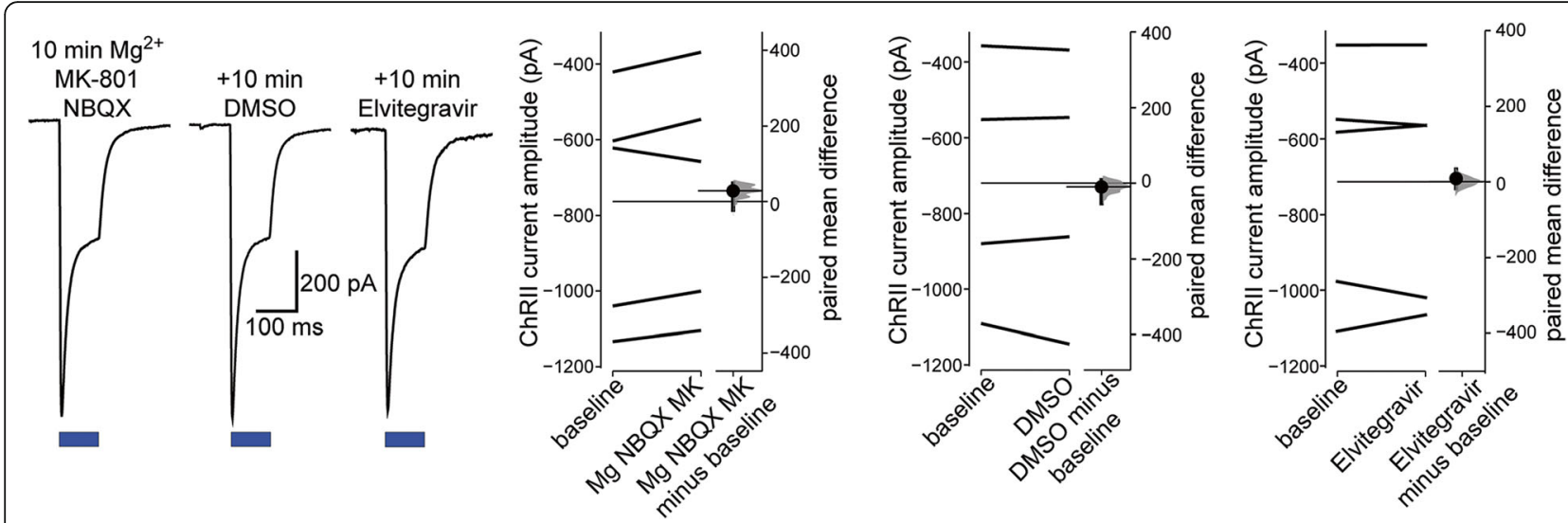

Fig. 6 Characterization and validation of ChRIl activation with light. On the left are representative whole-cell patch clamp recordings (Vhold= $-70 \mathrm{mV}$ ) from an mCherry-positive neuron in a DIV 16 primary hippocampal culture infected with rAAVs encoding for mCherry and the channelrhodopsin-2 (ChRII) mutant T159C on DIV 8. Recordings were made from the same cell after 10 min sequential application of blockers

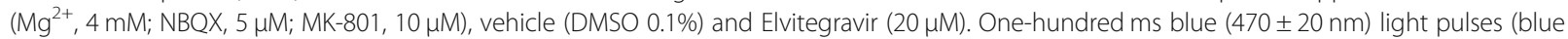
bars) evoke downward inward current deflections with prominent inactivation over the $100 \mathrm{~ms}$ pulse duration. The raw response amplitude data for all cells ( $N=4$ or 5$)$ is plotted on the right as paired observations connected by a line and the paired mean difference is plotted as a bootstrap distribution. Mean differences are depicted as dots with the $95 \%$ confidence intervals indicated by the vertical error bars. The $p$ values of the two-sided permutation $t$-tests are: baseline vs Mg/NBQX/MK-801, 0.125; baseline vs DMSO, 0.757; baseline vs Elvitegravir, 0.747

$\mathrm{Mg}^{2+}$. Elvitegravir also showed no effect on the amplitude of NMDA receptor-mediated EPSCs over a $20 \mathrm{~min}$ period (Fig. 7c). Thus Elvitegravir blocked neither the presynaptic release probability of glutamate nor the postsynaptic AMPA and NMDA receptors that glutamate activates.

\section{Discussion}

While pro-death signaling of extrasynaptic NMDA receptors is a common trigger of neuronal cell death in a wide range of neurodegenerative diseases, the NMDA receptor itself is not well-suited as a drug target $[3,9]$. Therefore, to develop novel therapeutic strategies, it is important to identify compounds that act downstream of toxic NMDA receptor signaling. In this study, we developed a screening method to identify neuro- and mitoprotective compounds in mouse primary cortical neurons. This screening method is robust, scalable, and does not require specialized equipment or reagents. Compared to other commonly used methods that depend on enzymatic reactions to quantify cell death, such as quantification of lactate dehydrogenase (LDH) release or ATP levels, our microscopy-based screening method is highly cost-effective.

The hits that were identified in our screen include a number of previously described neuroprotective compounds. The antipsychotic drug Haloperidol has been described to protect striatal neurons against NMDA toxicity in vivo, most likely via interaction with the NMDA receptor $[34,35]$ but see [36]. The $5 \alpha$-reductase inhibitors Finasteride and Dutasteride have been shown to protect against chemical ischemia and mitochondrial permeability transition in cultured neurons, most likely via modulation of voltage-gated potassium channels [37]. Enalapril (Vasotec) is an inhibitor of angiotensin converting enzyme and has been shown to protect against glutamate-mediated cell death in vitro and against focal cerebral ischemia in rats in vivo, via radical scavenging [38, 39]. These findings suggest that our screening method can reliably detect neuroprotective compounds that act via diverse targets and signaling mechanisms.

In our follow-up experiments we focused on the antiretroviral compound Elvitegravir, as it has not previously been described as neuroprotective. Elvitegravir is an integrase inhibitor that is used to treat HIV infection. Its neuroprotective effect, however, cannot be explained by inhibition of viral integrase enzymes that are absent in naïve primary neurons. This is supported by our finding that the related integrase inhibitor Raltegravir was not neuroprotective in our screen and suggests an off-target effect being responsible for neuroprotection. Based on our electrophysiological characterization, its target is not the NMDA receptor. Thus, Elvitegravir exerts its neuroprotective effect by acting on a yet to be identified target that is located downstream of the NMDA receptor and upstream of mitochondrial membrane potential breakdown.

Administration of Elvitegravir following the excitotoxic insult failed to provide neuroprotection in our study. Thus, Elvitegravir is unlikely to be effective in treating acute insults like ischemic stroke or brain trauma. It might be effective, however, in the treatment of diseases that involve chronic glutamate toxicity, such as Alzheimer's disease, Huntington's disease, Amyotrophic Lateral Sclerosis, 




and Multiple Sclerosis. As an FDA-approved drug that has been used in a large number of patients for many years, the safety profile of Elvitegravir is well established. For a potential treatment of neurodegenerative diseases, however, considerable drug development appears necessary, including, e.g., an improvement of Elvitegravir's bloodbrain-barrier permeability [40,41]. Toxic side-effects of prolonged Elvitegravir exposure are likely due to its activation of the integrated stress response (ISR) [27]. Further investigation of the mechanism of Elvitegravir's off-target 
neurotoxic effect might identify strategies to attenuate its long-term toxicity. A promising example is the application of the small molecule ISR inhibitor, trans-ISRIB [27]. Alternatively, a combinatorial chemistry or structure-based computational drug screen approach might identify compounds similar to Elvitegravir without neurotoxic sideeffects. To assess the applicability of improved Elvitegravir derivatives, their neuroprotective properties should be assessed in a range of neurotoxicity paradigms such as glutamate toxicity, oxygen-glucose deprivation, and oxidative stress. Although our in vitro electrophysiological .experiments did not provide evidence for an effect of Elvitegravir on glutamatergic synapses, the in vivo situation might be different. Given its low permeability through the blood-brain-barrier, potential neuroactive properties of Elvitegravir are unlikely to adversely affect the brain. This might be an issue, however, with modified compounds that have improved blood-brain-barrier permeability. Therefore, to assess the in vivo safety of improved Elvitegravir derivatives, potential effects on learning and memory should be tested. In recent years, several genetic and pharmacological strategies for mitoprotection have been shown to be effective in protecting against excitotoxic cell death in vitro and in vivo [23, 25, 42-46]. Our study identifies Elvitegravir as a novel, clinically approved compound for mitoprotective drug development and reports a robust, simple, and cost-effective screening method that might help identify additional drug candidates in the future.

\section{Supplementary information}

Supplementary information accompanies this paper at https://doi.org/10. 1186/s13041-020-00641-1.

Additional file 1. Table S1.

Additional file 2. Table S2.

Additional file 3: Supplementary Movie 1. 20-min time-lapse imaging of primary cortical neurons stained with TMRE following NMDA $(30 \mu \mathrm{M})$ insult in the presence or absence of $10 \mu \mathrm{M}$ protective

compound. Image stacks were registered and have equivalent contrast to enable comparison.

\section{Abbreviations}

AMPA: 2-amino-3-(3-hydroxy-5-methyl-isoxazol-4-yl) propanoic acid; APV: DL2-amino-5-phosphonopentanoic acid; ChRII: Channelrhodopsin-2; DIV: Days in vitro; DMSO: Dimethylsulfoxide; EGTA: Ethylene glycol tetraacetic acid; EPSC: Excitatory post synaptic current; GABA: Gamma-aminobutyric acid; NBQX: 2,3-Dioxo-6-nitro-1,2,3,4-tetrahydrาobenzo [f]quinoxaline-7sulfonamide; NMDA: N-methyl-D-aspartate; rAAV: Recombinant adenoassociated virus; TMRE: Tetramethylrhodamine ethyl ester

\section{Acknowledgements}

We thank Holger Erfle, Jürgen Reymann, Manuel Gunkel, and Jürgen Beneke (Advanced Biological Screening Facility at BioQuant, Heidelberg University) for assistance during assay development, Iris Bünzli-Ehret for her help with the preparation of hippocampal cultures, and Abigail Marklew and her colleagues, Charles River Chesterford Research Park, for her help with HEK293 cell electrophysiology.

\section{Authors' contributions}

$\mathrm{CBO}$ and $\mathrm{HB}$ initiated and designed the study. SM and CBO developed the screening assay and performed cell death and TMRE assays. CT performed the electrophysiological recordings. SM, CPB, CP, AMH and CBO analyzed data. $\mathrm{SM}$ and $\mathrm{CBO}$ wrote the manuscript with input from all coauthors. All authors read and approved the final manuscript.

\section{Funding}

This work has been supported by the Deutsche Forschungsgemeinschaft (FOR 2289: BA1007/9-1, BA1007/9-2, BA3679/4-2; SFB 1134), European Research Council (ERC) Advanced Grant (233024). The funding bodies had no role in the design of the study and collection, analysis, and interpretation of data and in writing the manuscript. H.B. is a member of the Excellence

Cluster CellNetworks at Heidelberg University.

\section{Availability of data and materials}

The datasets used and/or analyzed during the current study are available from the corresponding author on reasonable request.

\section{Ethics approval and consent to participate}

All animal experiments were carried out in accordance with German guidelines for the care and use of laboratory animals and with the European Community Council Directive 2010/63/EU. Experiments were approved by local authorities (Regierungspraesidium Karlsruhe, Germany).

\section{Consent for publication}

Not applicable.

\section{Competing interests}

The authors declare that they have no competing interests.

Received: 10 June 2020 Accepted: 8 July 2020

Published online: 14 September 2020

\section{References}

1. Amantea D, Bagetta G. Excitatory and inhibitory amino acid neurotransmitters in stroke: from neurotoxicity to ischemic tolerance. Curr Opin Pharmacol. 2017;35:111-9.

2. Lau A, Tymianski M. Glutamate receptors, neurotoxicity and neurodegeneration. Pflug Arch Eur J Phy. 2010;460(2):525-42.

3. Bading $\mathrm{H}$. Therapeutic targeting of the pathological triad of extrasynaptic NMDA receptor signaling in neurodegenerations. J Exp Med. 2017;214(3): $569-78$.

4. Macrez R, Stys PK, Vivien D, Lipton SA, Docagne F. Mechanisms of glutamate toxicity in multiple sclerosis: biomarker and therapeutic opportunities. Lancet Neurol. 2016;15(10):1089-102.

5. Nicholls DG. Mitochondrial calcium function and dysfunction in the central nervous system. Biochim Biophys Acta. 2009;1787(11):1416-24.

6. Brookes PS, Yoon Y, Robotham JL, Anders MW, Sheu SS. Calcium, ATP, and ROS: a mitochondrial love-hate triangle. Am J Physiol-Cell Ph. 2004;287(4): C817-33.

7. Briston T, Selwood DL, Szabadkai G, Duchen MR. Mitochondrial permeability transition: a molecular lesion with multiple drug targets. Trends Pharmacol Sci. 2019;40(1):50-70.

8. Kroemer G, Galluzzi L, Brenner C. Mitochondrial membrane permeabilization in cell death. Physiol Rev. 2007;87(1):99-163.

9. Lai TW, Zhang S, Wang YT. Excitotoxicity and stroke: identifying novel targets for neuroprotection. Prog Neurobiol. 2014;115:157-88.

10. Ogden KK, Traynelis SF. New advances in NMDA receptor pharmacology. Trends Pharmacol Sci. 2011;32(12):726-33.

11. Ikonomidou C, Turski L. Why did NMDA receptor antagonists fail clinical trials for stroke and traumatic brain injury? Lancet Neurol. 2002;1 (6):383-6.

12. Hardingham GE, Fukunaga Y, Bading H. Extrasynaptic NMDARs oppose synaptic NMDARs by triggering CREB shut-off and cell death pathways. Nat Neurosci. 2002;5(5):405-14.

13. Hardingham GE, Bading $\mathrm{H}$. Synaptic versus extrasynaptic NMDA receptor signalling: implications for neurodegenerative disorders. Nat Rev Neurosci. 2010:11(10):682-96.

14. Leveille F, El Gaamouch F, Gouix E, Lecocq M, Lobner D, Nicole O, et al. Neuronal viability is controlled by a functional relation between synaptic and extrasynaptic NMDA receptors. FASEB J. 2008;22(12):4258-71. 
15. Ahlgren $\mathrm{H}$, Bas-Orth C, Freitag HE, Hellwig A, Ottersen OP, Bading H. The nuclear calcium signaling target, activating transcription factor 3 (ATF3), protects against dendrotoxicity and facilitates the recovery of synaptic transmission after an excitotoxic insult. J Biol Chem. 2014:289(14):9970-82.

16. Arnold FJ, Hofmann F, Bengtson CP, Wittmann M, Vanhoutte P, Bading $H$. Microelectrode array recordings of cultured hippocampal networks reveal a simple model for transcription and protein synthesis-dependent plasticity. J Physiol. 2005;564(Pt 1):3-19.

17. Berndt A, Schoenenberger P, Mattis J, Tye KM, Deisseroth K, Hegemann P, et al. High-efficiency channelrhodopsins for fast neuronal stimulation at low light levels. Proc Natl Acad Sci U S A. 2011;108(18):7595-600.

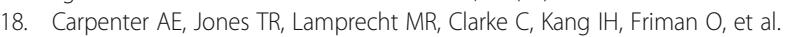
CellProfiler: image analysis software for identifying and quantifying cell phenotypes. Genome Biol. 2006;7(10):R100.

19. Schindelin J, Arganda-Carreras I, Frise E, Kaynig V, Longair M, Pietzsch T, et al. Fiji: an open-source platform for biological-image analysis. Nat Methods. 2012:9(7):676-82.

20. Thevenaz P, Ruttimann UE, Unser M. A pyramid approach to subpixel registration based on intensity. IEEE Trans Image Process. 1998;7(1):27-41.

21. Ho J, Tumkaya T, Aryal S, Choi H, Claridge-Chang A. Moving beyond P values: data analysis with estimation graphics. Nat Methods. 2019;16(7):565-6.

22. Babicki S, Arndt D, Marcu A, Liang Y, Grant JR, Maciejewski A, et al. Heatmapper: web-enabled heat mapping for all. Nucleic Acids Res. 2016; 44(W1):W147-53.

23. Qiu J, Tan YW, Hagenston AM, Martel MA, Kneisel N, Skehel PA, et al. Mitochondrial calcium uniporter Mcu controls excitotoxicity and is transcriptionally repressed by neuroprotective nuclear calcium signals. Nat Commun. 2013:4:2034

24. Lau D, Bengtson CP, Buchthal B, Bading H. BDNF reduces toxic extrasynaptic NMDA receptor signaling via synaptic NMDA receptors and nuclear-calciuminduced transcription of inhba/Activin A. Cell Rep. 2015;12(8):1353-66.

25. Zhang SJ, Zou M, Lu L, Lau D, Ditzel DA, Delucinge-Vivier C, et al. Nuclear calcium signaling controls expression of a large gene pool: identification of a gene program for acquired neuroprotection induced by synaptic activity. PLoS Genet. 2009;5(8):e1000604.

26. Banker G, Goslin K. Culturing nerve cells. 2nd ed. Cambridge: MIT Press; 1998.

27. Stern AL, Lee RN, Panvelker N, Li J, Harowitz J, Jordan-Sciutto KL, et al. Differential effects of antiretroviral drugs on neurons in vitro: roles for oxidative stress and integrated stress response. J Neuroimmune Pharm. 2018;13(1):64-76.

28. Lau D, Bading H. Synaptic activity-mediated suppression of p53 and induction of nuclear calcium-regulated neuroprotective genes promote survival through inhibition of mitochondrial permeability transition. J Neurosci. 2009;29(14):4420-9.

29. Nicholls DG. Fluorescence measurement of mitochondrial membrane potential changes in cultured cells. Methods Mol Biol. 2018;1782:121-35.

30. Bonci A, Williams JT. Increased probability of GABA release during withdrawal from morphine. J Neurosci. 1997:17(2):796-803.

31. Debanne D, Guerineau NC, Gahwiler BH, Thompson SM. Paired-pulse facilitation and depression at unitary synapses in rat hippocampus: quantal fluctuation affects subsequent release. J Physiol. 1996;491(Pt 1):163-76.

32. Regehr WG. Short-term presynaptic plasticity. C S H Perspect Biol. 2012;4(7): a005702.

33. Zucker RS, Regehr WG. Short-term synaptic plasticity. Annu Rev Physiol. 2002;64:355-405.

34. McDonald JW, Johnston MV. Pharmacology of N-methyl-D-aspartateinduced brain injury in an in vivo perinatal rat model. Synapse. 1990;6(2): 179-88.

35. Fletcher EJ, MacDonald JF. Haloperidol interacts with the strychnineinsensitive glycine site at the NMDA receptor in cultured mouse hippocampal neurones. Eur J Pharmacol. 1993;235(2-3):291-5.

36. Nasrallah HA, Chen AT. Multiple neurotoxic effects of haloperidol resulting in neuronal death. Ann Clin Psychiatry. 2017;29(3):195-202.

37. Soskic, Vukic, and André Schrattenholz. Use of finasteride, dutasteride and related compounds for the prevention or treatment of neurologicallyassociated disorders. U.S. patent no. 7,998,970. 2011.

38. Kaur P, Muthuraman A, Kaur M. The implications of angiotensin-converting enzymes and their modulators in neurodegenerative disorders: current and future perspectives. ACS Chem Neurosci. 2015;6(4):508-21.
39. Ravati A, Junker V, Kouklei M, Ahlemeyer B, Culmsee C, Krieglstein J. Enalapril and moexipril protect from free radical-induced neuronal damage in vitro and reduce ischemic brain injury in mice and rats. Eur J Pharmacol. 1999:373(1):21-33.

40. Gong Y, Chowdhury P, Nagesh PKB, Rahman MA, Zhi K, Yallapu MM, et al. Novel elvitegravir nanoformulation for drug delivery across the blood-brain barrier to achieve HIV-1 suppression in the CNS macrophages. Sci Rep. 2020;10(1):3835.

41. Ntshangase S, Mdanda S, Naicker T, Kruger HG, Baijnath S, Govender T. Spatial distribution of elvitegravir and tenofovir in rat brain tissue: application of matrix-assisted laser desorption/ionization mass spectrometry imaging and liquid chromatography/tandem mass spectrometry. Rapid Commun Mass Spectrom. 2019;33(21):1643-51.

42. Zhang SJ, Steijaert MN, Lau D, Schutz G, ucinge-Vivier C, Descombes P, et al. Decoding NMDA receptor signaling: identification of genomic programs specifying neuronal survival and death. Neuron. 2007;53(4):549-62.

43. Angelova PR, Vinogradova D, Neganova ME, Serkova TP, Sokolov W, Bachurin SO, et al. Pharmacological sequestration of mitochondrial calcium uptake protects neurons against glutamate excitotoxicity. Mol Neurobiol. 2019;56(3):2244-55.

44. Kostic M, Ludtmann MH, Bading H, Hershfinkel M, Steer E, Chu CT, et al. PKA phosphorylation of NCLX reverses mitochondrial calcium overload and depolarization, promoting survival of PINK1-deficient dopaminergic neurons. Cell Rep. 2015;13(2):376-86.

45. McManus MJ, Murphy MP, Franklin JL. The mitochondria-targeted antioxidant MitoQ prevents loss of spatial memory retention and early neuropathology in a transgenic mouse model of Alzheimer's disease. J Neurosci. 2011;31(44):15703-15.

46. Kim H, Lee JY, Park KJ, Kim WH, Roh GS. A mitochondrial division inhibitor, Mdivi-1, inhibits mitochondrial fragmentation and attenuates kainic acidinduced hippocampal cell death. BMC Neurosci. 2016;17(1):33.

\section{Publisher's Note}

Springer Nature remains neutral with regard to jurisdictional claims in published maps and institutional affiliations.
Ready to submit your research? Choose BMC and benefit from:

- fast, convenient online submission

- thorough peer review by experienced researchers in your field

- rapid publication on acceptance

- support for research data, including large and complex data types

- gold Open Access which fosters wider collaboration and increased citations

- maximum visibility for your research: over $100 \mathrm{M}$ website views per year

At BMC, research is always in progress.

Learn more biomedcentral.com/submissions 